\title{
Individual and community-level determinants of cervical cancer screening in Zimbabwe: a multilevel analysis of a nationwide survey
}

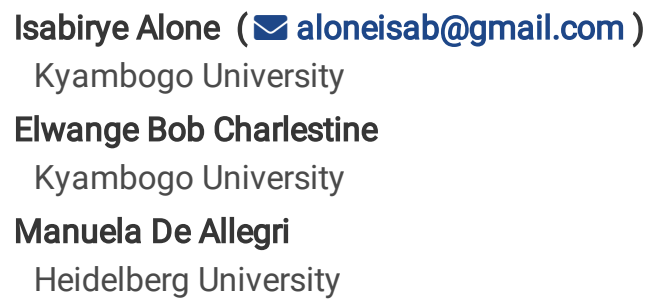

\section{Research Article}

Keywords: Screening, Cervical cancer, Zimbabwe

Posted Date: February 21st, 2022

DOI: https://doi.org/10.21203/rs.3.rs-1351262/v1

License: (c) (i) This work is licensed under a Creative Commons Attribution 4.0 International License. Read Full License 


\section{Abstract}

Cervical cancer screening that has proven to reduce the burden of cervical cancer elsewhere, but remains low in Zimbabwe, a country with the highest disease burden in Sub-Saharan Africa. The ministry of health's 2018-target was to screen $25 \%$ of the women aged 25-59 years though cross-sectional district-based studies have indicated sub-optimal screening. The main objective of the study was to establish the determinants of cervical cancer screening in Zimbabwe using multi-level modelling to take into account individual, household, and community factors simultaneously. We used data from the 2015 Zimbabwe Demographic and Health Survey including 9955 women aged 15-49 years nested within 400 communities. We used two-step multi-level multivariable regression analyses. Few (13.44\%) women had ever screened for cervical cancer. We observed higher odds of ever been screened among women; aged $31-49$ years $(\mathrm{OR}=2.01 ; 95 \% \mathrm{Cl} 1.72-2.34)$, working $(\mathrm{OR}=1.35 ; 95 \% \mathrm{Cl} 1.17-1.55)$, with health insurance (OR $=1.95 ; 95 \% \mathrm{Cl} 1.63-2.34)$, who ever used modern contraceptives ( $\mathrm{OR}=1.51 ; 95 \% \mathrm{Cl} 1.22-1.86)$, with exposure to multiple media $(\mathrm{OR}=1.27 ; 95 \% \mathrm{Cl} 1.03-1.58)$, and residing in communities with high proportion of women with; favorable attitude towards wife beating (OR $=1.21 ; 95 \% \mathrm{Cl} 1.04-1.41)$, and with a non-poor wealth index distribution ( $\mathrm{OR}=1.54 ; 95 \% \mathrm{Cl} 1.14-2.05)$. The study findings point at the co-existence of individual and community factors in shaping decision to screen and call for policies that address inequities in access to resources as well as disempowering cultural attitudes.

\section{Background}

Cervical cancer ranks fourth as the most common cancer globally. It accounts for almost $50 \%$ of new cases of cancer and for $33 \%$ of cancer-related deaths per annum worldwide ${ }^{1}$. There is intense inequality in incidence globally since the biggest cervical cancer burden ( $84 \%$ of new cases and $87 \%$ of the deaths) occur in Low and Middle Income Countries (LMICs) ${ }^{1}$. In high-income countries, widespread cytology-based screening has resulted in decreased incidence and mortality from cervical cancer ${ }^{2}$. On the opposite, due to poor access and concomitant low uptake of cervical cancer screening, Low and Middle Income Countries (LMICs) have not seen similar improvements. In most cases, incidence and mortality in LMICs continue to rise ${ }^{3}$. for instance, 542 and 1368 cases of cervical cancer were reported in 2008 and 2015 respectively in Zimbabwe ${ }^{4}$. The gap in the burden of cervical cancer that exists between developed and Low and Middle Income Countries (LMICs) could be narrowed if LMICs embraced HPV vaccination and regular cervical cancer screening programs. Even with attainment of universal HPV vaccination, cervical cancer screening would remain important because the existing HPV vaccines target a limited number of HPV strains ${ }^{5}$.

WHO is cognizant of the fact that the target age, intervals, and frequency of cervical cancer screening are determined by existing infrastructure, resources, costs, burden of the disease, and the willingness of the respective governments ${ }^{7}$. However, WHO recommends that women age 30 years ought to initiate cervical cancer screening ${ }^{6}$. Additionally, cervical cancer screening programs are recommended to target women age 30-49 years because of the elevated risk of HPV-positivity in the age-group. By targeting the 30-49 age group, screening even once would be beneficial rather than maximizing the number of screening tests in a woman's course-of-life ${ }^{6}$. Several cervical cancer screening approaches exist including; simple and convenient visual tests [with Lugol's iodine (VILI) or acetic acid (VIA)], the Papanicolaou test (Pap smear), and HPV-DNA testing ${ }^{8}$. Despite the differences in the sensitivity of the above-stated screening approaches, they have been proven to be effective for cervical cancer screening ${ }^{8,9}$. Of the four screening approaches, HPV-DNA testing approach is more reliable (high sensitivity) and convenient (self-collection of samples), however, the approach cannot be used for detecting pre-cancer cells; it has to be followed by one of the visual tests especially when the HPV-DNA result is positive. This is why the WHO organization recommend the use of VIA/ VILI in resource limited settings because, it is affordable, and women can be screened and treated in a single visit 8,9 . Additionally, WHO highly recommend HPV-DNA testing followed by the visual tests in settings where staged screening can be sustained economically; HPV-DNA testing helps in detecting high risk HPV among women and the visual tests helps in isolating HPV-positive women who are eligible for treatment ${ }^{7}$.

Countries in Southern Africa experience the highest disease burden due to cervical cancer. The region has an age-standardized incidence rate of 43.1 and age-standardized mortality rate of 20 compared to the global estimate of 14.0 and 6.8 respectively 10 . Among countries in Southern Africa, Zimbabwe carries the highest burden, with an age-standardized incidence rate of 62.3 per 100,000 women, implying that the country experiences about five times more cases than the global average. Besides, the agestandardized mortality rate of 46.0 per 100,000 women places the country close to seven times the global average ${ }^{11}$. The Zimbabwe National Cancer Registry (ZNCR) reported that in 2015, 30.8\% and $26.6 \%$ of all malignancies observed among women of

Page $2 / 23$ 
all races in Bulawayo and black women in Harere respectively were attributable to cervical cancer ${ }^{4}$. Similarly, estimates indicate in Zimbabwe, in 2018, about 3186 women were newly diagnosed with and 2151 succumbed to cervical cancer ${ }^{12}$. The Zimbabwe's cervical cancer cases registered in 2008 (542 cases), 2011 (1133 cases), and 2015 (1368 cases) depict a trajectory trend, demonstrating an increasing burden of the disease in the country ${ }^{4}$.

Cervical cancer screening remains available only in a selected public health facilities, rendering itself to obvious access challenges ${ }^{13}$ for a primarily rural population. Although private health facilities in Zimbabwe supplement public health facilities in providing cervical cancer screening services, they are also not easily accessible due to cost barriers ${ }^{13}$ especially for the $38.3 \%$ poor Zimbabweans ${ }^{14}$. In 2012, Zimbabwe adopted Visual Inspection with Acetic Acid and Cervicography (VIAC) in public health facilities

15. At these facilities, women who test/ screen VIAC positive are treated immediately. Methods including, loop electrosurgical excision procedure (LEEP), cauterization, and cryotherapy are used under the see and treat model. Women with potential cancer lesions are referred to the next level of care for biopsies ${ }^{15}$.

The 2018 ministry of health target was to screen $25 \%$ of the women aged $25-59$ years ${ }^{13}$. Zimbabwean women have shown high levels of awareness ${ }^{16,17}$ and expressed positive attitudes towards cervical cancer screening ${ }^{18,19}$ in spite of the abovementioned challenges associated with accessing it ${ }^{15}$. Accordingly, prior population-based studies have indicated low service uptake with estimates suggesting that the proportion of women who ever underwent screening stands at $9 \%$ in Shamva rural district 20 , at $5 \%$ in Hurungwe rural district ${ }^{21}$, and at $5.8 \%$ in Chegutu rural district ${ }^{17}$. Higher rates of $26.8 \%$ and $34 \%$ were detected in Gweru ${ }^{18}$ and in Kwekwe ${ }^{19}$, but with samples being drawn at district, and hospital level respectively. An additional study reported a decline in the uptake of VIAC, especially between 2014 and $2016^{22}$.

Existing evidence underscores the role of data on cervical cancer screening in guiding successful interventions ${ }^{23,24}$. Some cervical cancer prevention interventions did not make breakthroughs because of lack of direction, negative perception, lack of scope, and limited acceptance caused by their rollout before gathering sufficient evidence concerning population-specific factors ${ }^{25,26}$. Limited evidence exists on the determinants of utilization of cancer screening opportunities in Zimbabwe. Qualitative studies have indicated that negative religious beliefs ${ }^{17,18}$, inadequate knowledge regarding CC and screening ${ }^{19}$, and unavailability of screening services at women's usual points of health care ${ }^{17}$ may play a role, while a quantitative study in Shamva rural district indicated that financially independent women had 0.066 higher odds of having ever screened for cervical cancer compared with their husband-financiallydependent counterparts ${ }^{20}$. The policy relevance of existing studies, however, is limited by small and largely facility-based samples, in addition majority of the aforementioned studies focused on one type of residence, and lacked national scope. Hence, a comprehensive understanding of how individual, household, and community factors come together to shape uptake of cervical cancer screening is still missing. Our work aims to fill this gap in knowledge by examining the prevalence of cervical cancer screening, and its associated factors using multi-level modeling to inform the design of future screening programs in Zimbabwe.

\section{Methods}

\section{Data sources}

The study used secondary data from the 2015 Zimbabwe Demographic and Health Survey (ZDHS). The ZDHS contains important national health and demographic variables. Administratively, Zimbabwe is divided into 10 provinces. Each of the ten provinces is constituted by districts, and a district is constituted by wards. The 2012 Zimbabwe population census sub-divided each ward into Enumeration Areas (EAs) for convenience ${ }^{27}$. The ZDHS is a nationally representative cross-sectional survey that applied a stratified two-stage cluster sampling design ${ }^{28}$, drawing from the 2012 population and housing census ${ }^{27}$. In the first stage, EAs/ villages/ clusters were randomly selected followed by households in the second stage. Women age 15-49 who were either permanent residents or visitors who slept in the selected household before the survey were considered ${ }^{28}$. A comprehensive explanation of the sampling approach is published in the ZDHS report ${ }^{28}$. We used 2015 ZDHS individual members' recode, and took all women (9955) from 10 provinces who were relevant to our study. The 2015 ZDHS selected the 9955 women from all the provinces including; Manicaland (1019 women), Mashonaland central (993 women), Mashonaland East (910 women), Mashonaland West (1054 
women), Matabeleland North (849 women), Matabeleland South (829 women), Midlands (1062 women), Masvingo (1046 women), Harare (1235 women), and Bulwayo (658 women). ${ }^{28}$.

\section{Variables And Their Measurements Outcome variable}

The outcome variable "ever been screened for cervical cancer" was measured using the question: "Have you ever been screened for cervical cancer?" (No/Yes). This question was asked to all women aged 15-49 years. Building on the abovementioned question, we constructed the outcome variable "ever screened for cervical cancer" as a binary variable taking value 1 if yes and 0 if no.

\section{Explanatory Variables}

Individual and community characteristics were examined for possible association with cervical cancer screening in Zimbabwe. The composition of the complete list of variables depended on what was contained in the dataset, and guided by existing studies 20,29-32. Individual-level variables considered for the study include: the women's age, religion, employment status, health insurance coverage, region, contraceptive use, total children ever born, type of marriage, household size, and place of delivery. Variables including; age, religion, working status, health insurance coverage, ever used modern family planning methods, and total children ever born were dichotomized. Additionally, age at first sex was Quadripartitioned while education level, amount of media exposure, type of marriage, household size, and place of delivery were trichotomized. Wealth index and region were categorized into five and six respectively. The categorization of the abovementioned variables was guided by existing literature related to the subject $20,31,32$. The 2015 ZDHS dataset captured 10 regions which we categorized into six; regions with related names were categorized into one to obtain fewer categories. Wealth index was a composite score pre-measured by household assets such as televisions, bicycles, materials used for house construction, water access types, sanitation facilities, and other characteristics related to wealth. Factor scores of household assets were generated through a principal component analysis and were then standardized and categorized into quintiles (poorest, poorer, middle, richer, and richest) ${ }^{28}$.

\section{Community-level Determinants}

Community-level factors were conceptualized as a set of variables capturing community disadvantages, i.e. factors that may make it difficult for people living in certain areas to achieve positive life outcomes. The nested nature of the 2015 ZDHS dataset enabled the use of multi-level logistic regression with the aim of isolating the contribution of individual-level from community-level factors with regard to cervical cancer screening. The Socio-Economic Indexes for Areas (SEIFA) approach was used to identify community disadvantages/ advantages ${ }^{33}$. With the exception of type of residence, the 2015 ZDHS did not collect data on community measures. Therefore, individual responses of women were aggregated to their respective communities to obtain community disadvantages. We defined community variables in relation to the 400 communities considered by the 2015 ZDHS. Specific community measures include: decision-making autonomy, attitudes towards wife-beating, type of residence, perceived distance to a health facility, and community-level socioeconomic status. The aforementioned variables have been derived and used as measures of community disadvantages by studies elsewhere ${ }^{34,35}$.

We measured two aspects of women's autonomy/ empowerment: decision-making power in the household and attitudes towards wife-beating. Decision-making power in the household was measured using the answers to the following three questions: the questions as to who decides matters pertaining to (a) the woman's health (personal decision-making authority), (b) visits to friends or family (mobility decision-making authority), and (c) food to be cooked each day. First, we generated an individual level indicator by differentiating women who made all three aforementioned decisions, either alone or jointly with their spouses, as having high decision-making autonomy, from women who did not as having low decision-making autonomy. Second, we aggregated scores of individuals at community level to derive the proportion of women with high decision-making autonomy for every community/ cluster. 
Attitudes towards wife-beating or domestic violence were assessed by asking women if they believed that a man had a right to beat his wife for five hypothetical scenarios: (1) she goes out without telling him, (2) she neglects the children, (3) she argues with him,

(4) she refuses to have sexual intercourse with him, and (5) she does not cook food properly. Similarly to what described above, we first classified individual responses, differentiating women as having a favorable attitude towards domestic violence when responding positively to at least one of the five scenarios and as having a negative attitude against domestic violence otherwise. Then, we aggregated values at community level to derive the proportion of women with favorable attitude towards wife beating.

The 2015 ZDHS posed a question "Do you perceive distance to a health facility to be a big challenge" with no/ yes responses. We used this variable as a proxy-measure for community disadvantage in terms of access to health facilities. Women who responded that distance was a big challenge in accessing health facilities were established and total number per community obtained. For the 400 communities, the minimum score was 0 , and the maximum was 27 , with a mean score of 7 . Clusters that had scores above the mean were categorized as communities with higher proportion of women who reported distance to the health facility as a big challenge (coded 0 ) and vice-versa. The aforementioned wealth indices for women were aggregated at their respective villages to obtain aggregate community socio-economic disadvantages. This was done by classifying women with middle, richer and richest wealth indices as having non-poor wealth index and proportions for each community/ cluster were established. The community-level socioeconomic measure was obtained by categorizing clusters into those with high and low proportions of women with a non-poor wealth index. This approach of measuring socioeconomic disadvantages has been used by studies in Kenya ${ }^{34}$ and Korea ${ }^{36}$. The composition of group-constructs from individual-level survey dataset is benefitial especially where multi-level models ${ }^{37}$ are deployed to provide evidence regarding the contribution of community-level factors ${ }^{33}$. The categories and the hypothesized direction of the association between explanatory variables and the outcome variable are summarized in Table 1. 
Table 1

Categories of individual-level and community-level variables with their hypothesized direction of association

\begin{tabular}{|c|c|c|c|}
\hline Variable & Variable & Categorization & \\
\hline \multirow[t]{3}{*}{ Outcome } & Ever been screened for CC & $0=\mathrm{No}$ & \\
\hline & & $1=$ Yes & \\
\hline & & & $\begin{array}{l}\text { Expected sign of association with } \\
\text { ever been screened for CC (Yes) }\end{array}$ \\
\hline \multirow{5}{*}{$\begin{array}{l}\text { Explanatory } \\
\text { variables } \\
\text { (Individual } \\
\text { level } \\
\text { variables) }\end{array}$} & Highest educational level attained & $\begin{array}{l}0=\text { Primary or } \\
\text { no education }\end{array}$ & \multirow[t]{3}{*}{+} \\
\hline & & 1 = Secondary & \\
\hline & & $\begin{array}{l}2 \geq \text { Post- } \\
\text { secondary }\end{array}$ & \\
\hline & \multirow[t]{2}{*}{ Age } & $0 \leq 30$ & \multirow[t]{2}{*}{+} \\
\hline & & $1=31-49$ & \\
\hline & \multirow[t]{7}{*}{ Region } & $\begin{array}{l}0= \\
\text { Manicaland }\end{array}$ & \multirow[t]{7}{*}{+} \\
\hline & & 1 = Masvingo & \\
\hline & & $\begin{array}{l}2= \\
\text { Mashonaland }\end{array}$ & \\
\hline & & $\begin{array}{l}3= \\
\text { Matabeleland }\end{array}$ & \\
\hline & & $4=$ Midlands & \\
\hline & & $5=$ Harare & \\
\hline & & $6=$ Bulwayo & \\
\hline & \multirow[t]{3}{*}{ Total children ever born } & $0 \leq 1$ & \multirow[t]{3}{*}{+} \\
\hline & & $1=2$ & \\
\hline & & $2 \geq 3$ & \\
\hline & \multirow[t]{2}{*}{ Currently working } & $0=$ No & \multirow[t]{2}{*}{+} \\
\hline & & $1=$ Yes & \\
\hline & \multirow[t]{2}{*}{ Religion } & $0=$ Christians & \multirow[t]{2}{*}{-} \\
\hline & & $\begin{array}{l}1=\text { Non- } \\
\text { Christians }\end{array}$ & \\
\hline & \multirow[t]{4}{*}{ Age at first sex } & $0 \leq 17$ & \multirow[t]{4}{*}{+} \\
\hline & & $1=18-22$ & \\
\hline & & $2=23-37$ & \\
\hline & & $3=$ Singles & \\
\hline & \multirow[t]{2}{*}{ Covered by health insurance } & $0=$ No & \multirow[t]{2}{*}{+} \\
\hline & & $1=$ Yes & \\
\hline & \multirow[t]{2}{*}{ Currently using any modern family planning method } & $0=$ No & \multirow[t]{2}{*}{+} \\
\hline & & $1=$ Yes & \\
\hline
\end{tabular}




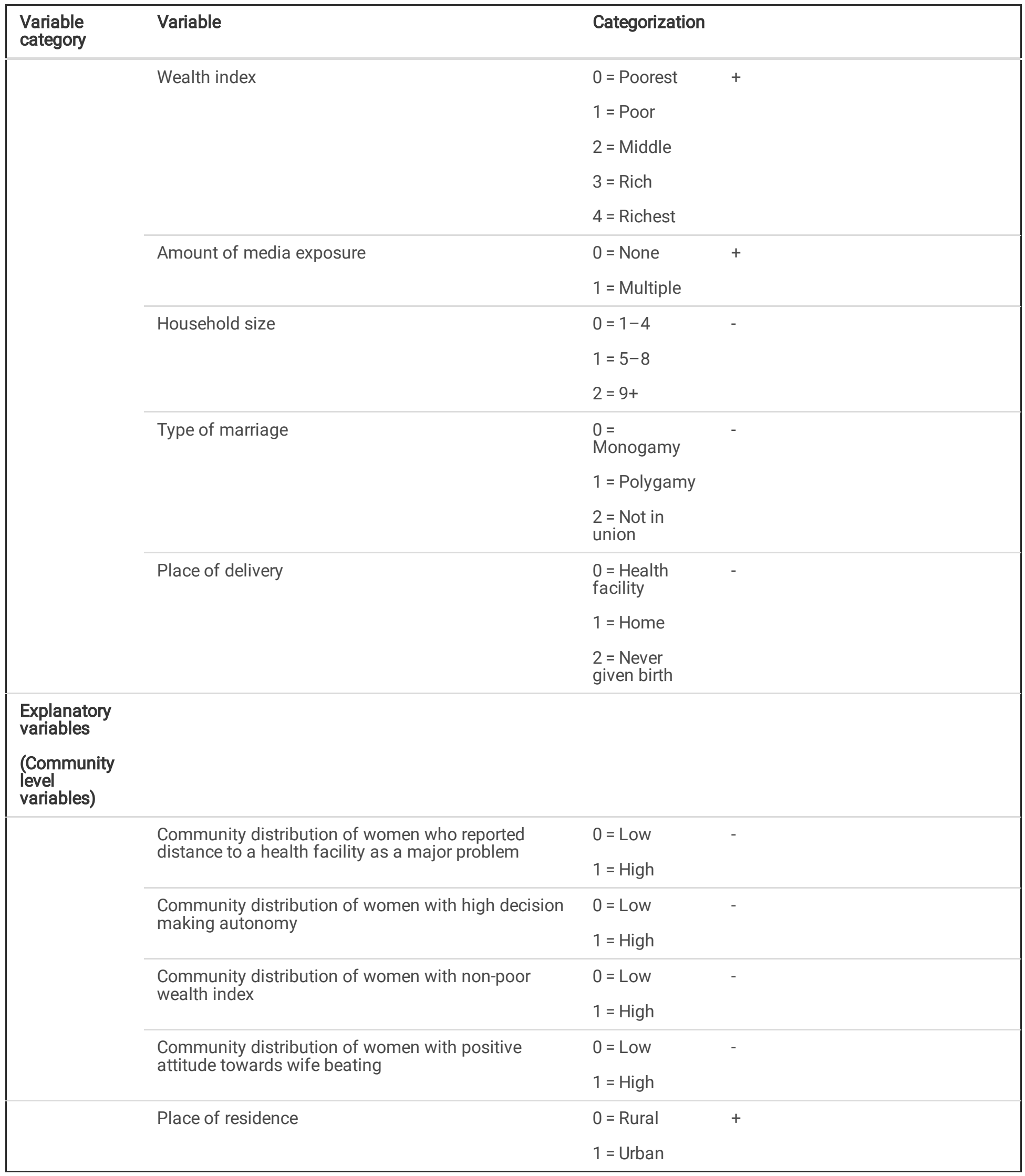

\section{Statistical Analyses}

We used frequency distributions to describe women's demographic and socioeconomic characteristics. We used cross-tabulation and applied Pearson's chi-squared $\left(x^{2}\right)$ tests to investigate associations of individual and community level characteristics with 
uptake of cervical cancer screening. The definition of the outcome variable as dichotomous and the hierarchical nature of the Zimbabwe DHS dataset enabled the use of the two-step multi-variable multilevel logistic regression with the log-binomial function of the generalized linear mixed models family ${ }^{38}$. The associations of individual-level and community-level determinants with uptake of cervical cancer screening were analyzed in a stepwise manner. The nesting of individuals within communities in which women lived generated three models for analysis. We started by fitting the variance component model or empty model (null model) (Eq. 1); the empty model excluded the fixed effects.

$\log \left(\frac{\Pi_{i j}}{1-\Pi_{i j}}\right)=\beta_{0}+\cup_{0 j}$ Eq. 1

Where; $\Pi_{i j}$ is the probability of woman $\mathrm{i}$ in community $\mathrm{j}$ having ever screened, $1-\Pi_{i j}$ is the probability of woman $\mathrm{i}$ in community $\mathrm{j}$ not having ever screened, $\beta_{0}$ is an intercept shared by all communities, and $U_{0 j}$ is the random effect specific to the community. The variance component model was constructed to determine whether the variation in uptake of cervical cancer screening could be explained by variations in communities in which women live (model including random effects only). This was attained by establishing the Intra-Cluster Correlation coefficients (ICCs), or Variance Partition Coefficients, or $\rho$ (the Greek rho). Mathematically, $\rho$ or ICC is obtained by dividing the proportion of variance at the group level with the total variances at the individual and group levels (Eq. 2) ${ }^{39}$.

ICC or $\rho=\frac{S_{b}^{2}}{\left(S_{b}^{2}+S_{W}^{2}\right)}$ Eq. 2

Where $S_{b}^{2}$ is the variance between clusters, and $S_{W}^{2}$ is the variance within clusters. We fitted model 2 adding all the individual-level factors (Eq. 3).

$$
\log \left(\frac{p_{i j}}{1-p_{i j}}\right)=\beta_{0 j}+\beta_{1} \boldsymbol{X}_{1 i}+\mathrm{U}_{0 j} ; i=1,2,3, \ldots n \quad \text { Equation } 3
$$

Finally, model 3 was fitted comprising individual-level and community-level determinants (Eq. 4).

$$
\log \left(\frac{p_{i j}}{1-p_{i j}}\right)=\beta_{0 j}+\beta_{1} \boldsymbol{X}_{1 i j}+\mathrm{U}_{0 j} ; i=1,2,3, \ldots n ; j=1,2,3, \ldots h \quad \text { Equation } 4
$$

Where; $X_{i j}=\left(X_{1 i j}, X_{2 i j}, \ldots, X_{q i j}\right)$ represents the first (women level factors) and the second level covariates (community level factors), $\beta_{0}, \beta_{1}, \beta_{2}, \ldots, \beta_{q}$ are regression coefficients, and $u_{0 j}, u_{1 j}, u_{2 j}, \ldots, u_{k j}$ are the random effect of model parameter at level two. The random effect is assumed to follow a normal distribution with variance $\sigma^{2} \mu 0$. To assess the fitness of model 3 relative to model 2, we estimated the likelihood ratio test and Akaike Information Criterion (AIC) of the two models; with a lower AIC value denoting a better model fit ${ }^{40}$. The odds of cervical cancer screening while controlling for individual-level and community-level determinants in model 3 were presented with their accompanying P-values and $95 \%$ confidence intervals ${ }^{41}$. We performed Variance Inflation Factor (VIF) and Tolerance test to check for multicollinearity among the covariates in the models. No multicollinearity problems were observed in the regression models since all variance inflation factor values were less than 10 and tolerance values were greater than 0.1. Stata SE 15 software was deployed for the analyses and the two-tailed Wald test was used to determine the statistical significance of the covariates at significance level of alpha equal to $5 \%{ }^{39}$.

\section{Ethical Considerations}

All data used in the study were obtained in fully anonymized format from the 2015 ZDHS, as such no targeted ethical approval was required for completion of this study. Data collection was conducted in accordance with Helsinki declaration for conducting research involving humans. During data collection, written informed consent was obtained from each respondent before the interviews ${ }^{28}$. Procedures and questionnaires for standard DHS surveys have been reviewed and approved by the ICF International Institutional 
Review Board (IRB). We obtained approval to use the data from the DHS repository (http://dhsprogram.com/data/availabledatasets.cfm).

\section{Results}

\section{Descriptive characteristics}

The prevalence of uptake of cervical cancer screening and the distribution of respondents by demographic and socio-economic characteristics are shown in Table 2. The study findings indicate that nearly 1 in 10 women $(13.44 \%)$ had ever screened for cervical cancer. Among the poorest, prevalence was slightly lower at 5.07\%. Results in Table 2 also reveal that over half of the respondents were $\leq 30$ years (59.38\%), in monogamous marital relationships (54.6), and had attained secondary education (66.67\%). Nearly half $(49.50 \%)$ were not working, and living in households with 5-8 members (45.6\%). Most of the women were not covered by health insurance (87.79\%), and had $\leq 3$ children (78.7\%). About 1 in 3 were residing in the region of Mashonaland (29.7\%), and had never used any form of modern contraception (31.45\%). Close to one-third were age $\leq 17$ years at first sexual intercourse (36.58\%) and nearly all (94.27\%) women were Christians. Close to a quarter did to have access to any form of media (24.24\%) and approximately 4 in 10 gave birth from a health facility (41.18\%). Considering community-level variables, over half were residing in communities with high proportions of women; supportive to wife beating (61.73\%), with non-poor wealth index (51.62\%) and urban dwelling (54.59\%). Relatedly over half of the women were residing in communities with low proportions of women with; high decision-making autonomy (56.18\%), and with challenges in accessing health care due to distance (59.53\%).

Bivariate analysis revealed a significant relationship between cervical cancer screening and all individual-level factors. The proportion of women who had ever screened was relatively higher among women who were; age $31-49$ years $(p<0.001)$, Christians $(p<0.026)$, had tertiary education or higher $(p<0.001)$, working $(p<0.001)$, covered by health insurance $(p<0.001)$, from Mashonaland region $(p<0.001)$, using any modern method of contraception $(p<0.001)$, having $\leq 4$ children $(p<0.001)$, age 23-37 years at first sex $(p<0.001)$, the richest $(p<0.001)$, exposed to multiple sources of media $(p<0.001)$, in monogamous marital relationships $(p<0.001)$, living in household with $1-4$ members $(p<0.001)$, and had delivered from health facilities $(p<0.001)$. The percentage of women had ever screened was also relatively higher among women who were living in communities with high proportion of women with; favorable attitude towards wife beating $(p<0.001)$, a non-poor wealth index $(p<0.001)$, and urban dwellers $(p<0.001)$. The percentage of women who had ever screened was relatively higher among women who were living in communities with low proportion of women who reported distance to health facility as a big challenge $(p<0.001)$. 
Table 2

distribution of women by individual characteristics and community characteristics by cervical cancer screening status ( $N=9955)$

\begin{tabular}{|c|c|c|c|c|}
\hline Characteristics & $\begin{array}{l}\text { Never } \\
\text { screened } \\
\mathrm{n}(\%)\end{array}$ & $\begin{array}{l}\text { Ever } \\
\text { screened } \\
\mathrm{n}(\%)\end{array}$ & $\begin{array}{l}\text { Sub-total } \\
\mathrm{n}(\%)\end{array}$ & $\begin{array}{l}\text { Chi- } \\
\text { squared p- } \\
\text { value }\end{array}$ \\
\hline Total & $8617(86.56)$ & 1338(13.44) & & \\
\hline Age group & & & & $P<0.001$ \\
\hline$\leq 30$ & $5457(92.32)$ & 454(7.68) & 5911(59.38) & \\
\hline $31-49$ & $3160(78.14)$ & 884(21.86) & 4044(40.62) & \\
\hline Religion & & & & $P=0.026$ \\
\hline Christians & $8106(86.37)$ & 1279(13.63) & 9385(94.27) & \\
\hline Non-Christians & 511(89.65) & $59(10.35)$ & $570(5.73)$ & \\
\hline Education level & & & & $P<0.001$ \\
\hline$\leq$ Primary & 2302(92.42) & 189(7.59) & 2491(25.02) & \\
\hline Secondary & $5757(86.74)$ & $880(13.26)$ & $6637(66.67)$ & \\
\hline Post-secondary & $558(67.47)$ & $268(32.53)$ & $827(8.31)$ & \\
\hline Currently working & & & & $P<0.001$ \\
\hline No & 4543(92.19) & $385(7.81)$ & 4928(49.50) & \\
\hline Yes & 4074(81.04) & $953(18.96)$ & $5027(50.50)$ & \\
\hline Covered by health insurance & & & & $P<0.001$ \\
\hline No & $7800(89.26)$ & 939(10.74) & 8739(87.79) & \\
\hline Yes & $817(67.19)$ & 399(32.18) & $1216(12.21)$ & \\
\hline Region & & & & $P<0.001$ \\
\hline Manicaland_ & 927(90.97) & $92(9.03)$ & 1019(10.24) & \\
\hline Mashonaland & $2587(87.49)$ & $370(12.51)$ & 2957(29.70) & \\
\hline Matabeleland & 1530(91.18) & 148(8.82) & 1678(16.86) & \\
\hline Midlands & 965(90.87) & 97(9.13) & 1062(10.67) & \\
\hline Masvingo & $909(86.90)$ & 137(13.10) & 1046(10.67) & \\
\hline Harare & $948(76.76)$ & 287(23.24) & 1235(12.41) & \\
\hline Bulwayo & 751(78.39) & 207(21.61) & 958(9.62) & \\
\hline Ever used modern contraceptives & & & & $p<0.001$ \\
\hline No & 2988(95.43) & $143(4.57)$ & $3131(31.45)$ & \\
\hline Yes & $5629(82.49)$ & 1195(17.51) & $6824(68.55)$ & \\
\hline Total children ever born & & & & $P<0.001$ \\
\hline$\leq 3$ & $6835(87.24)$ & $1000(12.76)$ & 7835(78.7) & \\
\hline$\geq 4$ & 1782(84.06) & 338(15.94) & 2120(21.3) & \\
\hline Age at first sex & & & & $P<0.001$ \\
\hline Never had sex & 1819(99.67) & $6(0.33)$ & 1825(18.33) & \\
\hline
\end{tabular}




\begin{tabular}{|c|c|c|c|c|}
\hline Characteristics & $\begin{array}{l}\text { Never } \\
\text { screened } \\
\mathrm{n}(\%)\end{array}$ & $\begin{array}{l}\text { Ever } \\
\text { screened } \\
\mathrm{n}(\%)\end{array}$ & $\begin{array}{l}\text { Sub-total } \\
\mathrm{n}(\%)\end{array}$ & $\begin{array}{l}\text { Chi- } \\
\text { squared p- } \\
\text { value }\end{array}$ \\
\hline$\leq 17$ & $3181(87.34)$ & $461(12.66)$ & $3642(36.58)$ & \\
\hline $18-22$ & $3121(82.09)$ & 681(17.91) & 3802(38.19) & \\
\hline $23-37$ & $496(72.30)$ & 190(27.70) & 686(6.89) & \\
\hline Wealth index & & & & $P<0.001$ \\
\hline Poorest & 1423(94.93) & $76(5.07)$ & $1499(15.06)$ & \\
\hline Poor & $1370(94.35)$ & $82(5.65)$ & 1452(14.59) & \\
\hline Middle & $1422(91.80)$ & $127(8.20)$ & $1549(15.56)$ & \\
\hline Rich & 2144(83.82) & $414(16.18)$ & $2558(25.70)$ & \\
\hline Richest & 2254(77.94) & $639(22.06)$ & 2897(29.10) & \\
\hline Amount of media exposure & & & & $P<0.001$ \\
\hline None & 2240(92.83) & $173(7.17)$ & 2413(24.24) & \\
\hline One & 2874(88.92) & $358(11.08)$ & $3232(32.47)$ & \\
\hline Multiple & $3503(81.28)$ & 807(18.72) & 4310(43.29) & \\
\hline Type of marriage & & & & $P<0.001$ \\
\hline Monogamy & $4471(82.26)$ & $964(17.74)$ & $5435(54.6)$ & \\
\hline Polygamy & $516(88.97)$ & $64(11.03)$ & $580(5.83)$ & \\
\hline Not in union & $3630(92.13)$ & $310(7.87)$ & $3940(39.58)$ & \\
\hline Household size & & & & $P<0.001$ \\
\hline $1-4$ & $3791(85.29)$ & $654(14.71)$ & $4445(44.65)$ & \\
\hline $5-8$ & 3946(86.94) & $593(13.06)$ & $4539(45.60)$ & \\
\hline $9+$ & $880(90.63)$ & $91(9.37)$ & $971(9.75)$ & \\
\hline Place of delivery & & & & $P<0.001$ \\
\hline Health facility & $3449(84.140$ & $650(15.86)$ & 4099(41.18) & \\
\hline Home & $698(95.10)$ & $35(4.90)$ & 734(7.37) & \\
\hline Never given birth & $4470(87.27)$ & $652(12.73)$ & $5122(51.45)$ & \\
\hline \multicolumn{5}{|l|}{ Independent variables (Community) } \\
\hline $\begin{array}{l}\text { Community distribution of women with favorable attitude } \\
\text { towards wife beating }\end{array}$ & & & & $P<0.001$ \\
\hline Low & $3488(91.55)$ & $322(8.45)$ & $3810(38.27)$ & \\
\hline High & $5129(83.47)$ & 1016(16.53) & $6145(61.73)$ & \\
\hline $\begin{array}{l}\text { Community distribution of women with high decision making } \\
\text { autonomy }\end{array}$ & & & & $P<0.001$ \\
\hline Low & 4925(88.06) & 668(11.94) & $5593(56.18)$ & \\
\hline High & 3692(84.64) & $670(15.36)$ & $4362(43.82)$ & \\
\hline Community distribution of women with a non-poor wealth index & & & & $P<0.001$ \\
\hline
\end{tabular}




\begin{tabular}{|c|c|c|c|c|}
\hline Characteristics & $\begin{array}{l}\text { Never } \\
\text { screened } \\
\text { n(\%) }\end{array}$ & $\begin{array}{l}\text { Ever } \\
\text { screened } \\
\mathrm{n}(\%)\end{array}$ & $\begin{array}{l}\text { Sub-total } \\
\mathrm{n}(\%)\end{array}$ & $\begin{array}{l}\text { Chi- } \\
\text { squared } p- \\
\text { value }\end{array}$ \\
\hline Low & $4477(92.96)$ & $339(7.04)$ & $4816(48.38)$ & \\
\hline High & $4140(80.56)$ & $999(19.44)$ & $5139(51.62)$ & \\
\hline $\begin{array}{l}\text { Community distribution of women that reported distance to } \\
\text { health facility as a big challenge }\end{array}$ & & & & $P<0.001$ \\
\hline Low & $4876(82.28)$ & 1050(17.72) & $5926(59.53)$ & \\
\hline High & $3741(92.85)$ & $288(7.15)$ & $4029(40.47)$ & \\
\hline Type of residence & & & & $P<0.001$ \\
\hline Rural & $5009(92.18)$ & $425(7.82)$ & $5434(54.59)$ & \\
\hline Urban & $3608(79.81)$ & 913(20.19) & $4521(45.41)$ & \\
\hline
\end{tabular}

Table 3 depicts the results of the multivariable multilevel regression analysis (MMLRA). We fitted the Variance Component Model (model I) first with the aim of determining the total variance in cervical cancer screening that can be attributed to the communities of residence. Results of Model I indicated a high $(0.56)$ and statistically significant $(p<0.001)$ variance partition coefficient (VPC) or intra-cluster correlation (ICC) indicating; a 56\% variation in cervical cancer screening as a result of women living in their respective communities and the appropriateness of deploying multi-level rather than individual-level analyses. The appropriateness of deploying multi-level analysis is supported by the statistically significant ICC $(p<0.001)$ that depicts the dependence in the data structure. The results of the Variance Component Model also provided estimations of community variance in form of median odds ratios $(\mathrm{MOR}=0.12)$, indicating a $12 \%$ less odds of having already screened for cervical cancer of women from an average community (results not shown in Table 3).

After running the null model (model 1), level one fixed effects (individual-level covariates) were controlled for in model II. Results obtained in Model II depict statistically significant $(p<0.001)$ proportional change $(-17)$ in community-level variance $(39 \%)$. A reduction in the community-level variance implied a reduction in the proportion of the unexplained variance arising from differences in communities. A reduction in the community-level variance also indicated the community differences in the frequency of individual factors in Zimbabwe supporting the use of multi-level analysis as well. After running the model with random effects as well as level one fixed effects (model II), level two fixed effects (community-level predictors) were controlled for in the mixed effects model (model III). It was observed that the community-level variance reduced marginally in model III suggesting similarity in the frequency of community-level determinants in all Zimbabwe communities. After controlling for individual-level and community-level factors, the variation in cervical cancer screening among communities remained significant.

\section{Fixed effects (measures of associations)}

Results from model II (comprised of only individual-level factors) indicate that the odds of cervical cancer screening were statistically significant, and higher among women; age $31-49$ years $(O R=2.01 ; 95 \% \mathrm{Cl} 1.72-2.34)$ than their counterparts age $\leq 30$ years, with secondary $(\mathrm{OR}=1.36 ; 95 \% \mathrm{Cl} 1.12-1.65)$ and tertiary $(\mathrm{OR}=1.68 ; 95 \% \mathrm{Cl} 1.27-2.23)$ compared to their counterparts with none or primary education, working $(\mathrm{OR}=1.35 ; 95 \% \mathrm{Cl} 1.17-1.55)$ than non-working, covered by health insurance $(\mathrm{OR}=1.94 ; 95 \% \mathrm{Cl}$ 1.61-2.33) than those without health insurance, ever used modern contraceptives $(\mathrm{OR}=1.54 ; 95 \% \mathrm{Cl} 1.25-1.90)$ than those who never used modern contraceptives, and initiated sex [at $\leq 17$ years ( $\mathrm{OR}=34.66 ; 95 \% \mathrm{Cl} 15.03-79.93), 18-22$ years $(\mathrm{OR}=30.99 ; 95 \%$ $\mathrm{Cl} 13.47-71.29), 23-37$ years $(\mathrm{OR}=33.81 ; 95 \% \mathrm{Cl} 14.46-79.05)]$ than women who never had sex, rich $(\mathrm{OR}=2.41 ; 95 \% \mathrm{Cl} 1.78-$ 3.24 ) and richest $(\mathrm{OR}=2.88 ; 95 \% \mathrm{Cl} 2.09-3.96)$ compared to their counterparts in poorest wealth quintile, had exposure to multiple media $(\mathrm{OR}=1.23 ; 95 \% \mathrm{Cl} 1.01-1.54$ ) than those exposed to none. However, the odds of uptake of cervical cancer screening were lower among women who did not deliver from health facilities $(\mathrm{OR}=0.49 ; 95 \% \mathrm{Cl} 0.34-0.70)$ than those who delivered from health facilities. Additionally, the Variance Partition Coefficients or $\rho$ (the Greek rho) (results not shown) revealed that $39 \%$ of the variance in cervical cancer screening was explained by common community characteristics $(\rho=0.39, p<0.0001)$. The results of model III (Table 3) indicate that the odds of cervical cancer screening were higher among women; age $31-49$ years $(\mathrm{OR}=2.01 ; 95 \% \mathrm{Cl} 1.72-$ 2.34) than their counterparts age $\leq 30$ years, working $(\mathrm{OR}=1.35 ; 95 \% \mathrm{Cl} 1.17-1.55)$ than non-working, with secondary education 
$(\mathrm{OR}=1.31 ; 95 \% \mathrm{Cl} 1.08-1.59)$ and post-secondary education $(\mathrm{OR}=1.63 ; 95 \% \mathrm{Cl} 1.23-2.16)$ compared to their counterparts with none or primary education, covered by health insurance $(\mathrm{OR}=1.95 ; 95 \% \mathrm{Cl} 1.63-2.34)$ than those without health insurance, ever used modern contraceptives $(\mathrm{OR}=1.51 ; 95 \% \mathrm{Cl} 1.22-1.86)$ than those who never used modern contraceptives, and had exposure to multiple media $(\mathrm{OR}=1.27 ; 95 \% \mathrm{Cl} 1.03-1.58)$ than those exposed to none, and rich $(\mathrm{OR}=1.52 ; 95 \% \mathrm{Cl} 1.06-2.20)$ and richest $(\mathrm{OR}=$ $1.64 ; 95 \% \mathrm{Cl} 1.09-2.47)$ compared to their counterparts in poorest wealth quintile. Considering age at first marriage, the odds of cervical cancer screening were higher among women whose age at first sex was $\leq 17$ years $(\mathrm{OR}=34.66$; $95 \% \mathrm{Cl} 15.03-79.93)$, $18-$ 22 years $(\mathrm{OR}=30.99 ; 95 \% \mathrm{Cl} 13.47-71.29), 23-37$ years $(\mathrm{OR}=33.81 ; 95 \% \mathrm{Cl} 14.46-79.05)$ than those who never had sex. However, the odds of uptake of cervical cancer screening were lower among women who did not deliver from health facilities $(O R=0.50 ; 95 \%$ $\mathrm{Cl}$ 0.35-0.72) than those who delivered from health facilities. Regarding community-level factors, the odds of cervical cancer screening were higher among women who were residing in communities with high proportion of women with; favourable attitude towards wife beating ( $\mathrm{OR}=1.21 ; 95 \% \mathrm{Cl} 1.04-1.41)$ than those residing in communities with low proportion with favourable attitude towards wife beating, and a non-poor wealth index $(\mathrm{OR}=1.54 ; 95 \% \mathrm{Cl} 1.14-2.05)$ than those residing in communities with low proportion of women with a non-poor wealth index. 
Table 3

Individual and community level determinants of cervical cancer screening

\begin{tabular}{|c|c|c|c|c|}
\hline \multirow[b]{2}{*}{ Fixed effects } & \multicolumn{2}{|c|}{$\begin{array}{l}\text { Model } 2 \text { including individual- } \\
\text { level determinants }\end{array}$} & \multicolumn{2}{|c|}{$\begin{array}{l}\text { Model } 3 \text { including community- } \\
\text { level determinants }\end{array}$} \\
\hline & OR & $(95 \% \mathrm{Cl})$ & OR & $(95 \% \mathrm{Cl})$ \\
\hline \multicolumn{5}{|c|}{ Individual-level Characteristics } \\
\hline \multicolumn{5}{|l|}{ Age group } \\
\hline \multicolumn{5}{|l|}{$\leq 30$ (Ref) } \\
\hline $31-49$ & 2.01 & $(1.72-2.34)^{\star \star \star}$ & 2.01 & $(1.72-2.34) * \star$ \\
\hline \multicolumn{5}{|l|}{ Religion } \\
\hline \multicolumn{5}{|l|}{ Christians (Ref) } \\
\hline Non-Christians & 0.93 & $(0.69-1.26)$ & 0.94 & $(0.70-1.26)$ \\
\hline \multicolumn{5}{|l|}{ Education level } \\
\hline \multicolumn{5}{|c|}{$\leq$ Primary (Ref) } \\
\hline Secondary & 1.36 & $(1.12-1.65)^{* *}$ & 1.31 & $(1.08-1.59){ }^{* *}$ \\
\hline Tertiary & 1.68 & $(1.27-2.23)^{* * *}$ & 1.63 & $(1.23-2.16){ }^{* *}$ \\
\hline \multicolumn{5}{|c|}{ Currently working } \\
\hline \multicolumn{5}{|l|}{ No (Ref) } \\
\hline Yes & 1.35 & $(1.17-1.55)^{* \star *}$ & 1.35 & $(1.17-1.55)^{\star \star \star}$ \\
\hline \multicolumn{5}{|c|}{ Covered by health insurance } \\
\hline \multicolumn{5}{|l|}{ No (Ref) } \\
\hline Yes & 1.94 & $(1.61-2.33)^{\star \star \star}$ & 1.95 & $(1.63-2.34)^{\star \star \star}$ \\
\hline \multicolumn{5}{|c|}{ Ever used modern contraceptives } \\
\hline \multicolumn{5}{|l|}{ No (Ref) } \\
\hline Yes & 1.54 & $(1.25-1.90)^{* \star *}$ & 1.51 & $(1.22-1.86)^{\star \star \star}$ \\
\hline \multicolumn{5}{|c|}{ Total children ever born } \\
\hline \multicolumn{5}{|l|}{$\leq 3$ (Ref) } \\
\hline$\geq 4$ & 1.08 & $(0.91-1.29)$ & 1.08 & $(0.90-1.29)$ \\
\hline \multicolumn{5}{|l|}{ Age at first sex } \\
\hline \multicolumn{5}{|c|}{ Never had sex (Ref) } \\
\hline$\leq 17$ & 34.42 & $(14.92-79.36)$ & 34.66 & $(15.03-79.93)$ \\
\hline $18-22$ & 31.09 & $(13.52-71.51)^{\star \star \star}$ & 30.99 & $(13.47-71.29)^{\star \star \star}$ \\
\hline $23-37$ & 34.74 & $(14.86-81.24)^{* * *}$ & 33.81 & $(14.46-79.05)^{* \star *}$ \\
\hline \multicolumn{5}{|l|}{ Wealth index } \\
\hline Poorest (Ref) & & & & \\
\hline
\end{tabular}

${ }^{\star} \mathrm{p}<0.05,{ }^{*} \mathrm{p}<0.01,{ }^{* \star} \mathrm{p}<0.001$, Ref $=$ Reference Category, OR = Odds Ratios, $\mathrm{Cl}=$ Confidence Interval 


\begin{tabular}{|c|c|c|c|c|}
\hline \multirow[b]{2}{*}{ Poor } & \multicolumn{2}{|c|}{$\begin{array}{l}\text { Model } 2 \text { including individual- } \\
\text { level determinants }\end{array}$} & \multicolumn{2}{|c|}{$\begin{array}{l}\text { Model } 3 \text { including community- } \\
\text { level determinants }\end{array}$} \\
\hline & 0.99 & $(0.71-1.38)$ & 0.95 & $(0.68-1.32)$ \\
\hline Middle & 1.32 & $(0.96-1.81)$ & 1.17 & $(0.85-1.62)$ \\
\hline Rich & 2.41 & $(1.78-3.24)^{* * *}$ & 1.52 & $(1.06-2.20)^{*}$ \\
\hline Richest & 2.88 & $(2.09-3.96)$ & 1.64 & $(1.09-2.47)^{*}$ \\
\hline \multicolumn{5}{|c|}{ Amount of media exposure } \\
\hline \multicolumn{5}{|l|}{ None (Ref) } \\
\hline One & 1.11 & $(0.90-1.36)$ & 1.12 & $(0.91-1.39)$ \\
\hline Multiple & 1.23 & $(1.01-1.54)^{*}$ & 1.27 & $(1.03-1.58) *$ \\
\hline \multicolumn{5}{|l|}{ Household size } \\
\hline \multicolumn{5}{|l|}{$1-4$ (Ref) } \\
\hline $5-8$ & 1.03 & $(0.90-1.18)$ & 1.05 & $(0.91-1.20)$ \\
\hline $9+$ & 1.00 & $(0.77-1.30)$ & 1.03 & $(0.79-1.35)$ \\
\hline \multicolumn{5}{|l|}{ Place of delivery } \\
\hline \multicolumn{5}{|l|}{ Health facility (Ref) } \\
\hline Home & 0.49 & $(0.34-0.70)$ & 0.50 & $(0.35-0.72) *$ \\
\hline Never given birth & 1.00 & $(0.87-1.16)$ & 1.00 & $(0.86-1.15)$ \\
\hline \multicolumn{5}{|c|}{ Community-level determinants } \\
\hline \multicolumn{5}{|c|}{$\begin{array}{l}\text { Community distribution of women with favorable attitude } \\
\text { towards wife beating }\end{array}$} \\
\hline \multicolumn{5}{|l|}{ Low (Ref) } \\
\hline High & & & 1.21 & $(1.04-1.41)$ * \\
\hline \multicolumn{5}{|c|}{$\begin{array}{l}\text { Community distribution of women with high decision } \\
\text { making autonomy }\end{array}$} \\
\hline \multicolumn{5}{|l|}{ Low (Ref) } \\
\hline High & & & 0.94 & $(0.80-1.10)$ \\
\hline \multicolumn{5}{|c|}{$\begin{array}{l}\text { Community distribution of women with a non-poor wealth } \\
\text { index }\end{array}$} \\
\hline \multicolumn{5}{|l|}{ Low (Ref) } \\
\hline High & & & 1.54 & $(1.14-2.05))^{* *}$ \\
\hline \multicolumn{5}{|c|}{$\begin{array}{l}\text { Community distribution of women that reported distance to } \\
\text { health facility as a big challenge }\end{array}$} \\
\hline \multicolumn{5}{|l|}{ Low (Ref) } \\
\hline High & & & 0.81 & $(0.65-1.02)$ \\
\hline \multicolumn{5}{|l|}{ Type of residence } \\
\hline Rural (Ref) & & & & \\
\hline
\end{tabular}

${ }^{*} \mathrm{p}<0.05,{ }^{*} \mathrm{p}<0.01,{ }^{* *} \mathrm{p}<0.001$, Ref $=$ Reference Category, OR = Odds Ratios, $\mathrm{Cl}=$ Confidence Interval 


\begin{tabular}{|lll|}
\hline & $\begin{array}{l}\text { Model } 2 \text { including individual- } \\
\text { level determinants }\end{array}$ & $\begin{array}{l}\text { Model } 3 \text { including community- } \\
\text { level determinants }\end{array}$ \\
\hline Urban & & 1.03 \\
\hline$* \mathrm{p}<0.05, * * \mathrm{p}<0.01, * * * \mathrm{p}<0.001$, Ref $=$ Reference Category, OR = Odds Ratios, $\mathrm{Cl}=$ Confidence Interval \\
\hline
\end{tabular}

\section{Discussion}

Our study makes an important contribution to the literature by investigating the influence of community and individual factors on uptake of cervical cancer screening using a nationally representative sample and accounting for individual, household, and community factors at once. Previous studies adopted a more narrow geographical scope as they focused on single/specific locations and analysis took into account individual level variables only ${ }^{17-19,22}$. To our knowledge, our study is the first of its kind to look at uptake for cervical cancer screening and its determinants using multi-level regression modeling on a national sample in Zimbabwe. The existing study ${ }^{34}$ was conducted in a different setting (Kenya) making the generalization of such findings to Zimbabwe unrealistic.

Overall prevalence of cervical cancer screening in Zimbabwe was low (13.44\%) among women age 15-49 years. Cervical cancer screening in Zimbabwe was not only shaped by individual level factors but by community-level factors as well. The key individuallevel factors that were significantly associated with higher odds of cervical cancer screening in Zimbabwe were; belonging to 31-49 age group, secondary or higher educational attainment, currently working, having health insurance, ever using contraceptives, having ever given birth to 4 or more children, age 17 or above at first sex, belonging to rich or higher wealth quintile, and exposure to multiple media. The key community-level factors that were significantly associated with higher odds of cervical cancer screening in Zimbabwe were living in communities with high proportion of women with; favorable attitude towards wife beating, and non-poor wealth index.

Although the prevalence of cervical cancer screening established by the current study was low (13.44\%), more women had embraced cervical cancer screening in Zimbabwe; this is because, earlier studies conducted in; Shamva district, Mashonaland central province, Zimbabwe (9\%) ${ }^{20}$, and Hurungwe rural district, Mashonaland West province, Zimbabwe (5\%) ${ }^{16}$ had established much lower prevalence of cervical cancer screening. The difference in cervical cancer prevalence between the former and current study may alternatively be explained by the fact that the former studies sampled one district while the latter considered nationwide sample. Studies from other countries in the region especially; South Africa ${ }^{42}$ and Botswana ${ }^{43}$ reported higher proportions (52\% and $72 \%$ respectively) of women who had ever screened for cervical cancer.

The results of our study revealed a statistically significant contribution of both individual-level and community-level factors towards the variation in cervical cancer screening. Higher significant odds of cervical cancer screening were associated with a number of individual-level sociodemographic factors in Zimbabwe. First, being aged 31-49 was significantly associated with higher odds of having ever screened for cervical cancer. The study findings are in consonance with findings of earlier studies in; Harare, Zimbabwe, a study reported 34 years as the median age for cervical cancer screening ${ }^{22}$, in Kenya, the odds of having ever screened for cervical cancer were higher among older women (aged 35-49 years) than their younger (aged 15-24 years) counter-parts ${ }^{34}$. Relatedly, older women were significantly associated with higher odds of having screened than younger women in Portland, Jamaica ${ }^{44}$, Ugrachandi Nala, Kavre, Nepal ${ }^{45}$, and Eastern China (among rural dwelling women) ${ }^{46}$. The finding of the current study may be attributed to tendency of women seeking screening at a later age after experiencing signs and symptoms of cervical cancer ${ }^{47,48}$. The abovementioned finding point to the importance of sensitizing younger women to screen for cervical cancer.

Secondly, the study results indicated higher likelihood of having ever screened for cervical cancer by working women compared to the non-working women. The findings of the current study concurs with the findings published by the 2015 Zimbabwe Demographic and Health Survey; over one-third (48\% urban and $34 \%$ rural) of the Zimbabwean women were not employed ${ }^{28}$. The study findings are also supported by results of a study conducted in Kenya which established a higher significant adjusted prevalence ratio for cervical cancer screening among working women than their non-working counterparts ${ }^{34}$. Employment of women contributes to their financial independence and overall uptake of reproductive health care services ${ }^{49}$, calling for interventions geared at empowering women economically. Similar to earlier studies, a higher likelihood of having ever screened for cervical cancer was observed among 
women covered by health insurance compared to their non-health insured counterparts. Relatedly, a study in Kenya indicated a higher significant controlled-for prevalence ratio for cervical cancer screening among women covered by health insurance than their non-health-insured counterparts ${ }^{34}$. This finding may be attributed to lack of screening among women without health insurance due to cost barriers; a situational analysis report highlighted cost as one of the main barriers to cervical cancer screening in Zimbabwe ${ }^{15}$. This study finding point to policy as well as logistical interventions to ensuring universal health insurance coverage since majority (89\%) of the Zimbabwean women are not covered by health insurance ${ }^{28}$.

Additionally, the current study established higher odds of cervical cancer screening among women who delivered from health facilities than those who did not deliver from health facilities. This finding is in agreement with findings of a study in Kenya which indicated a higher significant adjusted prevalence ratio for cervical cancer screening among women who had visited a health facility in the last 12 months compared to the baseline category (women who had not visited a health facility in the last 12 months) ${ }^{34}$. The probable explanation for the study finding is that contact with health providers have proven to have positive effects on cervical cancer screening uptake ${ }^{31,50}$. The finding of the current study suggest that health-facility delivery/ skilled birth attendance should be encouraged among Zimbabwean women because the practice is not only associated with pregnancy-related benefits ${ }^{51}$, but cervical cancer screening uptake as well.

The current study established higher odds of cervical cancer screening among women who ever used modern contraceptives than those who never used modern contraceptives. Contrary to the study findings, studies in Uganda did not find a significant relationship between use of modern contraception and cervical cancer screening ${ }^{31,50}$. This finding could be attributed to the benefits that were reaped from the use of pap smears as routine care for women receiving the Depo-Provera up to the late 1990s in Zimbabwe ${ }^{52}$ pointing to the importance of creating synergy between cervical cancer risk factors (contraceptives) program ${ }^{53}$ and cervical cancer screening.

The findings of the study indicated higher odds of cervical cancer screening among women who were already married compared to the never married women. The study result confirms to a finding that age at first marriage coincides with age at first sex and therefore exposure to HPV; almost all HPV infections occur within 3-4 years prior to first sexual intercourse ${ }^{5455}$. The plausible explanation for this finding is that the already married women may have screened for cervical cancer after experiencing the signs and symptoms. The above-mentioned finding point to the importance of adopting the recommendation (cervical cancer screening should start at age 21 or within three years of sexual debut and stop at age 70 or 3 or more negative tests within 10 years period) by the American Cancer Society ${ }^{56}$.

The current study further established higher odds of cervical cancer screening among women who had exposure to multiple media than those exposed to none. Elsewhere (Kenya), amount of media exposure was significantly associated with cervical cancer screening ${ }^{34}$. The probable reason for this finding is that media is a common channel through which health information is accessed 57. This finding point to the importance of drafting measures geared at empowering women economically in order to ensure access to multiple media. Access to multiple-media will enable acquisition of health information to facilitate informed health choices. Additionally social marketing campaigns/ programs about cervical cancer screening should adopt a media-mix approach of disseminating information about cervical cancer screening to women in order to reach the different segments of women in Zimbabwe ${ }^{58}$.

Higher significant odds of cervical cancer screening were not only associated with above-stated individual-level factors but with community-level factors as well. First, the odds of cervical cancer screening were higher among women who were residing in communities with high distribution of women with a non-poor wealth index than those residing in communities with low distribution of women with a non-poor wealth index. The finding of the current study are in agreement with finding of earlier studies; higher significant odds of having ever screened for cervical cancer were established among women who were residing in communities with higher wealth index in Zimbabwe ${ }^{20}$ and Eastern Jamaica ${ }^{44}$. However, our study findings are not supported by previous studies; in Kenya, there was no significant relationship between cervical cancer screening and overall wealth index of communities in which the women were dwelling ${ }^{34}$. This finding point to the importance of addressing factors responsible for economic disparities at community level. 
Surprisingly, the odds of cervical cancer screening were higher among women who were residing in communities with high distribution of women with favorable attitude towards wife beating/ domestic violence against women than those residing in communities with low distribution of women with favorable attitude towards wife beating/ domestic violence against women. The probable explanation for this finding is the pre-occupation of women with the psychology of violence and the acceptance of cultural orientations which is an attribute of patriarchal settings ${ }^{59,60}$. Slavery to the patriarchal sentiments is a manifestation of marital dependence ${ }^{61}$. There is scanty evidence with regard to marital relationships and cervical cancer screening calling for more research in this area. However, our study finding is not in agreement with previous research. A study in Kenya did not establish a significant relationship between the attitude of women towards domestic violence against women and cervical cancer screening ${ }^{34}$.

The low level of cervical cancer screening in Zimbabwe established by the current study may probably be explained by supply as well as demand related barriers. On the supply side, the grumbling economy of Zimbabwe have affected the health sector; for instance, it resulted into suspension of pap smears from the routine care menu for women in late 1990s due to inability to sustain the manpower and infrastructural requirements for the program ${ }^{52}$. The cervical cancer screening needs were left at the mercy of private providers which is cost prohibitive; the cost of cervical cancer screening in the private clinics is seven times the cost for the same service at National Family Planning Council service-centers ${ }^{15}$. Some of the demand-side barriers of cervical cancer screening reported by previous studies include; limited knowledge (20\%) of cervical cancer screening ${ }^{20}$. Our study findings point to the need for addressing supply related as well as demand related barriers; addressing supply related barriers to cervical cancer screening would call for measures to resuscitate the economy in order to create direct as well as spillover effects to the health sector in general and cervical cancer screening program in particular ${ }^{62}$. Sufficient funding of cervical cancer screening programs should be accompanied with sensitization of women about cervical cancer and cervical cancer screening to address knowledge gaps among women and increase voluntary cervical cancer screening uptake/ attendance 24,63 .

\section{Study Limitations}

Acknowledging a few limitations, we first note that relying exclusively on cross-sectional data, our analysis does not allow us to determine causation, but only to identify associations. Similarly, due to lack of relevant data, we could not assess the role that supply-side factors, such as availability and quality of services, play in shaping uptake of cervical cancer screening. The sampling error may have affected the precision of the findings since the study did not use census data. However, enumeration areas/ clusters were selected from the whole country to ensure representativeness of data and precise findings. Community-level variables were derived by aggregating individual responses to their respective clusters with an assumption of homogeneity of the clusters. Therefore associations at aggregated levels do not directly apply to individuals but to a group of individuals in a given cluster which calls for interpretation of the findings with such considerations. The dataset lacked data for variables related to social and environment context within the community. Therefore, total variance in cervical cancer screening explained by the current study excludes the effects of such aforementioned important community-level factors. For instance; relative lack of opportunities and weak social networks. Nonetheless, the multi-level regression models successfully isolated individual-level from community-level effects with reference to cervical cancer screening in Zimbabwe. The intra-cluster correlation coefficient (ICC) provided estimates for the variation in the components of the multilevel models notwithstanding the fact that it does not precisely indicate the extent of similarity in terms of ratings of women dwelling in the same village; the (within-group) interrater agreement (IRA). However, the coefficient shades light regarding the dependability of scores of participants in their respective clusters ${ }^{37}$.

\section{Conclusion}

The results of the current study provided nationally representative findings using the 2015 ZDHS dataset.

The study established that variation in cervical cancer screening in Zimbabwe was partially a function of individual level factors. Besides individual-level factors, the study findings also revealed that the variation of HPV vaccination in Zimbabwe was also as a result of community-level factors. The results of the current study call for; mobilizing women regarding issues of equality, and emphasis should be laid on demystifying cultural sentiments which insubordinates the women in their respective communities. Additionally economic empowerment programs should be rolled out to communities to empower women to be able to take charge of their health including cervical cancer screening. Universal National health insurance policy should be implemented to enable each

Page 18/23 
and every woman access health services including cervical cancer screening. The low rates of cervical cancer screening established by the current study also call for implementation of self-pap-smear-collection strategy. This is because, the self-sampling strategy can provide sensitivity comparable to clinician-collected-samples. Additionally, the self-sampling strategy is well tolerated by women ${ }^{64}$.

\section{Abbreviations}

$\mathrm{Cl}$

Confidence interval

FDA

Food and Drug Administration

HPV

Human papillomavirus

OR

Odds ratio

SDGs

Sustainable Development Goals SES:Socio-economic status

\section{Declarations}

\section{Ethics approval and consent to participate}

All data were obtained from the 2015 Zimbabwe Demographic and Health Survey (UDHS). Data collection was conducted in accordance with Helsinki declaration for conducting research involving humans. Written informed consent was got from each respondent prior to the interviews. Procedures and questionnaires for standard DHS surveys have been reviewed and approved by the ICF International Institutional Review Board (IRB). We obtained approval to use the data from the DHS repository (http://dhsprogram.com/data/available-datasets.cfm).

\section{Consent to publish}

Not applicable.

\section{Availability of data and materials}

Data are from the Demographic and Health Survey. The dataset is open to qualified researchers free of charge. To request access to the dataset, please apply at http://dhsprogram.com/data/Access-Instructions.cfm.

\section{Competing interests}

The authors declare that they have no competing interests.

\section{Funding}

None

\section{Author's contributions}

IA conceived and designed the study. He analyzed data with support from EBC and MDA. IA drafted the manuscript, with substantial contributions by EBC and MDA. All authors read and approved the final manuscript. 


\section{Acknowledgements}

The authors are grateful to Measures DHS for permitting us to explore the ZDHS dataset.

\section{Author's information}

IA is a Lecturer at the Department of Sociology, Anthropology, and Population Studies (Demography), Faculty of Social Sciences, Kyambogo University, Kampala, Uganda. IA holds a PhD in Population Studies of Makerere University, Kampala, Uganda. IA holds Masters of Science in Population and reproductive Health (Makerere University). His research interests are maternal and child health.

EBC is an Assistant Lecturer at Department of Sociology, Anthropology, and Population Studies (Demography), Faculty of Social Sciences, Kyambogo University, Kampala, Uganda. EBC holds Masters of Demography (Makerere University, Kampala, Uganda).

MDA is a Professor at Heidelberg Institute of Global Health, Medical Faculty and University Hospital, Heidelberg University, Im Neuenheimer Feld 130.3, 69120 Heidelberg, Germany

\section{References}

1. Bray F, Ferlay J, Soerjomataram I, Siegel RL, Torre LA JA. Global Cancer Statistics 2018: GLOBOCAN Estimates of Incidence and Mortality Worldwide for 36 Cancers in 185 Countries. Ca cancer j clin. 2018;00(00):1-31. doi:10.3322/caac.21492.

2. Castanon A., Landy R., Pesola F., Windridge P. SP. Prediction of cervical cancer incidence in England, UK, up to 2040, under four scenarios: a modelling study. Lancet Public Heal. 2018;3:34-43. doi:http://dx.doi.org/10.1016/ S2468-2667(17)30222-0

3. Wild CP, Weiderpass E, Stewart BW E. World Cancer Report: Cancer Research for Cancer Prevention. International Agency for Research on Cancer;; 2020. doi:http://publications.iarc.fr/586

4. Chokunonga E, Borok MZ, Chirenje ZM, Makunike-Mutasa R NN and NA. Pattern of Cancer in Zimbabwe in 2015, Zimbabwe National Cancer Registry (ZNCR). Published online 2017.

5. Munoz N, Bosch FX, de-Sanjose S, Herrero R, Castellsague X, Shah KV, Snijders JF ML. Epidemiologic Classification of Human Papillomavirus Types Associated with Cervical Cancer: the International Agency for Research on Cancer Multicenter Cervical Cancer Study Group. N Engl J Med. Published online 2013:1-10. www.nejm.org

6. WHO. Comprehensive Cervical Cancer Control; A Guide to Essential Practice. Second. WHO Press; 2014. www. who.int

7. WHO. WHO Guidelines: WHO Guidelines for Screening and Treatment of Precancerous Lesions for Cervical Cancer Prevention. Vol 60. WHO Press; 2013.

http://www.who.int/reproductivehealth/publications/cancers/screening_and_treatment_of_precancerous_lesions/en/index.html

8. De Vuyst H, Claeys P, Njiru S, et al. Comparison of pap smear, visual inspection with acetic acid, human papillomavirus DNAPCR testing and cervicography. Int J Gynecol Obstet. 2005;89(2):120-126. doi:10.1016/j.ijgo.2005.01.035

9. Mvundura M, Tsu V. Estimating the costs of cervical cancer screening in high-burden Sub-Saharan African countries. Int J Gynecol Obstet. 2014;126(2):151-155. doi:10.1016/j.ijgo.2014.02.012

10. Bruni L, Albero G, Serrano B, Mena M, Gómez D, Muñoz J, Bosch FX de SS. Human Papillomavirus and Related Diseases in Africa: Summary Report 17 June 2019: ICO/IARC Information Centre on HPV and Cancer (HPV Information Centre). Published online 2019.

11. Bruni L, Albero G, Serrano B, Mena M, Gómez D, Muñoz J, Bosch FX de SS. ICO/IARC Information Centre on HPV and Cancer (HPV Information Centre). Human Papillomavirus and Related Diseases in the World. Summary Report.; 2019. www.hpvcentre.net

12. Bruni L, Albero G, Serrano B, Mena M, Gómez D, Muñoz J, Bosch FX de SS. Human Papillomavirus and Related Diseases in Zimbabwe. Summary Report 17 June 2019. Published online 2019. www.hpvcentre.net

13. Ministry of Health and Child Care. The National Cancer Prevention And Control Strategy For Zimbabwe 2014-2018. Published online 2017. http://www.iccp-portal.org/sites/default/files/plans/\%0ACANCER STRATEGY FINAL 2013 2017.pdf

14. World Bank. Poverty headcount ratio at national poverty lines (\% of population) - Zimbabwe. Published 2020. Accessed November 18, 2020. https://data.worldbank.org/country/zimbabwe?

Page 20/23 
utm_content=bufferc6d6d\&utm_medium=social\&utm_source=twitter.com\&utm_campaign=buffer

15. Kuguyo O, Matimba A, Tsikai N, et al. Cervical cancer in Zimbabwe: a situation analysis. Pan Afr Med J. 2017;27(December):215. doi:10.11604/pamj.2017.27.215.12994

16. Fitzpatrick M, Pathipati M.P, McCarty K, Rosenthal A, Katzenstein D CZM and PB. Knowledge, attitudes, and practices of cervical Cancer screening among HIVpositive and HIV-negative women participating in human papillomavirus screening in rural Zimbabwe. BMC Womens Health. 2020;20(153). doi:https://doi.org/10.1186/s12905-020-01017-2

17. Nyamambi E, Murendo C, Sibanda N, Mazinyane S. Knowledge, attitudes and barriers of cervical cancer screening among women in Chegutu rural district of Zimbabwe. Cogent Soc Sci. 2020;6(1). doi:10.1080/23311886.2020.1766784

18. Mutambara J, Mutandwa P, Mahapa M, Chirasha V, Nkiwane S, Shangahaidonhi T. Knowledge, attitudes and practices of cervical cancer screening among women who attend traditional churches in Zimbabwe. J Cancer Res Pract. 2017;4(2):53-58. doi:10.1016/j.jcrpr.2017.02.001

19. Panganai T GC. Visual inspection with acetic acid screening for cervical cancer: perceptions of Zimbabwean women: A case of Kwekwe hospital. Int J Sport Exerc Heal Res. 2017;1(1):12-17. doi:10.31254/sportmed.1103

20. Mupepi SC, Sampselle CM, Johnson TR. Knowledge, attitudes, and demographic factors influencing cervical cancer screening behavior of Zimbabwean women. J Womens Heal. 2011;20(6):943-952. doi:10.1089/jwh.2010.2062

21. Fitzpatrick M, Pathipati MP, McCarty K, et al. Knowledge, attitudes, and practices of cervical Cancer screening among HIVpositive and HIV-negative women participating in human papillomavirus screening in rural Zimbabwe. BMC Womens Health. 2020;20(1):1-10. doi:10.1186/s12905-020-01017-2

22. Gabaza C, Chonzi P, Chadambuka A, Shambira G, Juru T.P, Gombe NT, Nsubuga P and TM. Utilization and outcomes of cervical cancer screening services in Harare City, 2012-2016: a secondary data analysis. BMC Health Serv Res. 2019;454(19). doi:https://doi.org/10.1186/s12913-019-4314-8

23. Alfaro. et al. Factors affecting attendance to cervical cancer screening among women in the Paracentral Region of El Salvador: a nested study within the CAPE HPV screening program. Published online 2015:1-8. doi:10.1186/s12889-015-2360-7

24. Abiodun OA, Olu-abiodun OO, Sotunsa JO OF. Impact of health education intervention on knowledge and perception of cervical cancer and cervical screening uptake among adult women in rural communities in Nigeria. BMC Public Health. 2014;814(14):19. http://www.biomedcentral.com/1471-2458/14/814

25. Black E, Hyslop F RR. Barriers and facilitators to uptake of cervical cancer screening among women in Uganda: a systematic review. BMC Womens Health. Published online 2019:1-12. https://doi.org/10.1186/s12905-019-0809-z

26. Craciun C, Baban A. "Who will take the blame ?": Understanding the reasons why Romanian mothers decline HPV vaccination for their daughters. Vaccine. 2012;30(48):6789-6793. doi:10.1016/j.vaccine.2012.09.016

27. Zimstat. Zimbabwe Population census 2012: Zimbabwe National Statistics Agency (Zimstat) Harare, Zimbabwe. Published online 2013.

28. Zimstat I. Zimbabwe Demographic and Health Survey 2015: Zimbabwe National Statistics Agency (Zimstat) Harare, Zimbabwe; The DHS Program ICF Rockville, Maryland, USA. Published online 2016.

29. Chowdhury MZI, Turin TC. Variable selection strategies and its importance in clinical prediction modelling. Fam Med Community Heal. 2020;8(1). doi:10.1136/fmch-2019-000262

30. Bursac Z, Gauss CH, Williams DK, Hosmer DW. Purposeful selection of variables in logistic regression. Source Code Biol Med. 2008;3:1-8. doi:10.1186/1751-0473-3-17

31. Ndejjo R, Mukama T, Musabyimana A MD. Uptake of Cervical Cancer Screening and Associated Factors among Women in Rural Uganda: A Cross Sectional Study. PLoS One. 2016;11(2):1-13. doi:10.1371/journal.pone.0149696

32. Mukama T, Ndejjo R, Musabyimana A, Halage AA, Musoke D. Women 's knowledge and attitudes towards cervical cancer prevention: a cross sectional study in Eastern Uganda. Published online 2017:1-8. doi:10.1186/s12905-017-0365-3

33. Price-Robertson R. What is community disadvantage? Understanding the issues, overcoming the problem. CAFCA Resour Sheet, Communities Fam Clear Aust. 2011;(May):1-10.

34. Tiruneh FN, Chuang K, Austin P, Ntenda M CY. Individual-level and community-level determinants of cervical cancer screening among Kenyan women: a multilevel analysis of a Nationwide survey. BMC Womens Health. 2017;109(17):1-14. doi:10.1186/s12905-017-0469-9

Page $21 / 23$ 
35. Kayode GA, Ansah E, Agyepong IA, Amoakoh-coleman M. Individual and community determinants of neonatal mortality in Ghana: a multilevel analysis. 2014;14(1):1-12. doi:10.1186/1471-2393-14-165

36. $\mathrm{Kim} \mathrm{H}$, Lee M, Kim H, et al. Factors affecting diabetic screening behavior of korean adults: A multilevel analysis. Asian Nurs Res (Korean Soc Nurs Sci). 2013;7(2):67-73. doi:10.1016/j.anr.2013.04.002

37. Van Mierlo H, Vermunt JK, Rutte CG. Composing group-level constructs from individual-level survey data. Organ Res Methods. 2009;12(2):368-392. doi:10.1177/1094428107309322

38. Gelman A HJ. Data Analysis Using Regression and Multilevel/Hierarchical Models. Cambridge University Press; 2006.

39. Browne WJ, Subramanian SV, Jones K GH. Variance partitioning in multilevel logistic models that exhibit overdispersion. R Stat Soc. 2005;168(3):599-613.

40. Akaike H. A New Look at the Statistical Model Identification. In:; 1974:716-724.

41. Schmidt C KT. When to use the odds ratio or the relative risk? Int J Public Heal. 2008;53:165-167.

42. Phaswana-Mafuya N, Peltzer K. Breast and cervical cancer screening prevalence and associated factors among women in the South African general population. Asian Pacific J Cancer Prev. 2018;19(6):1465-1470. doi:10.22034/APJCP.2018.19.6.1465

43. Mingo AM, Panozzo CA, Diangi YT, et al. Cervical cancer awareness and screening in Botswana. Int J Gynecol Cancer. 2012;22(4):638-644. doi:10.1097/IGC.0b013e318249470a

44. Ncube B, Bey A, Knight J, Bessler P JP. Factors Associated with the Uptake of Cervical Cancer Screening Among Women in Portland, Jamaica. N Am J Med Sci. 2015;7(3):1-10. doi:10.4103/1947-2714.153922

45. Pandey RA and KE. Cervical cancer screening behavior and associated factors among women of Ugrachandi Nala, Kavre, Nepal. Eur J Med Res. 2017;23(22). doi:DOI 10.1186/s40001-017-0274-9

46. Liu T, Li S, Ratcliffe J, Chen G. Assessing knowledge and attitudes towards cervical cancer screening among rural women in eastern China. Int J Environ Res Public Health. 2017;14(9):1-10. doi:10.3390/ijerph14090967

47. Ndlovu N KR. Factors associated with tumour stage at presentation in invasive cervical cancer. Cent Afr J Med. Published online 2003. doi:https://pubmed.ncbi.nlm.nih.gov/15298465/

48. Finocchario-Kessler S, Wexler C, Maloba M, Mabachi N, Ndikum-Moffor F BE. Cervical cancer prevention and treatment research in Africa: a systematic review from a public health perspective. BMC Womens Health. 2016;29(16):1-25. doi:10.1186/s12905016-0306-6

49. Kwagala B, Nankinga O, Wandera SO, Ndugga P, Kabagenyi A. Empowerment, intimate partner violence and skilled birth attendance among women in rural Uganda. Reprod Health. Published online 2016:1-9. doi:10.1186/s12978-016-0167-3

50. Isabirye A, Mbonye MK, Kwagala B. Predictors of cervical cancer screening uptake in two districts of Central Uganda. PLoS One. 2020;15(12 December):1-11. doi:10.1371/journal.pone.0243281

51. Ujjwal D, Barkha C HM. The Role of Place of Delivery in Preventing Neonatal and Infant Mortality Rate in India. Geographies. Published online 2021. file:///C:/Users/User/Downloads/geographies-01-00004.pdf

52. Moyo IM, Koni NP, Makunike B, Hipshman J, Makaure HK GN. Evaluation of cervical cancer screening programme in the Harare City Health Department, Zimbabwe. Cent Afr J Med. 1997;43(8):223-225. https://pubmed.ncbi.nlm.nih.gov/9431759/

53. Thomas DB RR. Oral contraceptives and invasive adenocarcinomas and adenosquamous carcinomas of the uterine cervix: the World Health Organization Collaborative Study of Neoplasia and Steroid Contraceptives. Am J Epidemiol. 1996;144:281-9.

54. WHO. WHO guidance note: comprehensive cervical cancer prevention and control: a healthier future for girls and women: World Health Organisation. Published online 2013. www.who.int

55. WHO. Guidelines for screening and treatment of precancerous lesions for cervical cancer prevention. WHO Guidel. Published online 2013:60.

http://www.who.int/reproductivehealth/publications/cancers/screening_and_treatment_of_precancerous_lesions/en/index.html

56. American Cancer Society. Testing for Cervical Cancer New recommendations from the American Cancer Society, American SocietyCA. (2012). Testing for Cervical Cancer New recommendations from the American Cancer Society, American Society for Colposcopy and Cervical Pathology, and. 2012;62(3):211-212. doi:10.3322/caac.21135.VOLUME

57. Institute of Medicine (US) Committee on Assuring the Health of the Public. Media. In: The Future of the Public's Health in the 21st Century. National Academies Press (US); 2003.

Page 22/23 
58. Hilde A.M and V. Media multitasking and the effectiveness of combining online and radio advertising. Comput Human Behav. Published online 2011. doi:10.1016/j.chb.2011.06.016

59. Guracho YD, Bifftu BB. Women 's attitude and reasons toward justifying domestic violence in Ethiopia: a systematic review and meta-analysis. 2018;18(4):1255-1266.

60. Sultana A. Patriarchy and Women's Subordination: A Theoretical Analysis. Arts Fac J. Published online 2012:1-18. doi:10.3329/afj.v4i0.12929

61. Straus DSK and MA. Wife's Marital Dependency and Wife Abuse. J Marriage Fam. 1982;44(2):277-286. doi:https://doi.org/10.2307/351538

62. Thoa NTM, Thanh NX, Chuc NTK, Lindholm L. The impact of economic growth on health care utilization: A longitudinal study in rural Vietnam. Int J Equity Health. 2013;12(1):1-6. doi:10.1186/1475-9276-12-19

63. Swanson M, Ibrahim S, Blat C, et al. Evaluating a community-based cervical cancer screening strategy in Western Kenya: A descriptive study. BMC Womens Health. 2018;18(1):1-10. doi:10.1186/s12905-018-0586-0

64. Singla A.A, Komesaroff P. Self-collected Pap smears may provide an acceptable and effective method of cervical cancer screening. Heal Sci Rep. 2018;1(5):33. doi:10.1002/hsr2.33 